\title{
Using Multimedia-Assisted LINCS for Learning English Pronunciation
}

\author{
https://doi.org/10.3991/ijet.v14i09.10356 \\ Hassan Saleh Mahdi \\ University of Bisha, Bisha, Saudi Arabia \\ almatari7@gmail.com, hsmohammed@ub.edu.sa
}

\begin{abstract}
Learning pronunciation can be enhanced by several strategies. LINCS (List, Identify, Note, Create, Self-test) is one of these strategies that can be used to help language learners learn and remember new words effectively. LINCS is an acronym of the following steps: List the words, identify a reminding word, note a LINCing story, create a LINCing picture, and self-test. LINCS can be implemented either traditionally (i.e. pen-and-paper) or with the help of multimedia. Previous studies examined the effect of traditional LINCS on learning pronunciation. However, no single study has examined the effect of LINCS enhanced by multimedia on pronunciation learning. Therefore, this study aims at investigating the effect of LINCS enhanced by multimedia on learning English pronunciation. Data were collected through pronunciation tests from $45 \mathrm{Ar}$ $\mathrm{ab}$ university learners of English as a foreign language. They were randomly assigned into three groups: Multimedia-assisted LINCS, Traditional LINCS, and a control group (No LINCS). The study is an experimental one in which pre- and a post-tests were administered to these groups. The results indicated that LINCS (either multimedia-assisted LINCS or traditional LINCS) is an effective way of improving learners' FL pronunciation. The participants in both experimental groups performed better than the participants in the control group.
\end{abstract}

Keywords - Learning pronunciation, multimedia, LINCS, strategy, foreign language.

\section{$1 \quad$ Introduction}

In order to be successful in language learning, learners need to have a large number of words. Learning words does not mean only to know their meaning. A number of aspects need to be mastered (Nation, 2001). Learning how to pronounce new words is a crucial factor. However, many EFL learners fail to master L2 pronunciation. The lack of mastering L2 pronunciation can be attributed to several factors. Gilakjani and Ahmadi (2011) listed a number of factors affecting the learning of pronunciation. These factors include accent, motivation, exposure to the target language, attitude, type of instruction, age, personality, and mother tongue influence. Learning pronunciation can be enhanced by several strategies. These strategies can help learners acquire new words and remember them longer. One of these strategies is LINCS. LINCS is a 
powerful strategy for memory enhancement in order to influence the students while learning words and their meaning and definition (Wong, 2004). The LINCS strategy is a strategy created to learn new words with their meanings through a memory device. The LINCS enables students to create a link word as a reminder word that sounds similar to the new word. Then, the reminder word should be linked to the short story that describes the target words using elements from the definition. Next, students draw an image that tells the story which ties with the definition of the new word.

LINCS can be combined with multimedia. This combination may increase the effectiveness of LINCS. For example, in traditional LINCS, static images are used, but in multimedia-assisted LINCS, motion images or videos can be used. This combination will increase the usefulness of LINCS based on Piovio (1997) Dual Coding Theory. As far as the author knows, no single study has been conducted to examine the effect of multimedia-assisted LINCS on learning FL pronunciation. Therefore, the present study aims at examining the impact of multimedia-assisted LINCS on learning FL pronunciation.

\section{Review of the Literature}

\subsection{Pronunciation and foreign language learning}

Pronunciation is an essential component of assessing oral communication and spoken proficiency (Iwashita, Brown, McNamara, \& O'Hagan, 2008). Pronunciation is an important element of learning a foreign language because mispronunciation may cause misunderstanding. Pennington and Richards (1986) defined pronunciation as the way to utter individual sounds, stress, and intonation patterns of the target language. The goal of learning a foreign language pronunciation is to achieve real communication and intelligibility between speakers (Jenkins, 2000). Pronunciation like a native speaker is often difficult; therefore, the tendency nowadays is to achieve the highest degree of comprehensibility (Kang, 2010). Comprehensible pronunciation is considered as the chief goal of pronunciation training (Morley, 1991) since perfect pronunciation is sometimes impossible and not necessary.

\subsection{Pronunciation learning strategies}

Second or foreign language learning is a daunting process for most learners. Although the external conditions are similar, there are significant differences in levels of achievement among individual language learners. One of the reasons for such differences is attributed to individual differences and attitudes, which could either inhibit or accelerate learning. These differences have been examined under the term language learning strategies. Therefore, the extent to which a learner succeeds in FL learning depends, among others, on the language learning strategies he or she deploys while studying an FL, and this includes pronunciation. Therefore, a number of studies have examined and proposed strategies for learning FL pronunciation. For example, Peterson (2000) proposes a definition of Pronunciation Learning Strategies (PLS) as "steps 
taken by students to enhance their own pronunciation learning" (p. 7). These steps are general approaches to pronunciation learning viewed by Peterson as strategies, which include specific actions, or tactics used as specific tools for successful strategic learning. A summary of these strategies and tactics is shown in Table 1 (based on Pawlak's, 2010; Peterson, 2000; Szysszka, 2017).

Table 1. A summary of pronunciation learning strategies

\begin{tabular}{|l|l|}
\hline \multicolumn{1}{|c|}{ Pronunciation learning strategies and tactics } \\
\hline 1 & Electronic devices and other works of reference for help \\
\hline 2 & Extemporaneous \\
\hline 3 & Forming associations with an already known pronunciation of TL and NL words \\
\hline 4 & Imitating native speakers' or/and teachers' pronunciation \\
\hline 5 & Learning about pronunciation rules \\
\hline 6 & Listening \\
\hline 7 & Listening to pronunciation errors made by TL speakers \\
\hline 8 & Maintaining a sense of humor with regard to pronunciation mistakes \\
\hline 9 & Minimal pairs \\
\hline 10 & Monologues \\
\hline 11 & Noticing and miming lip movements \\
\hline 12 & Noticing differences between NL and TL pronunciation \\
\hline 13 & Phonics \\
\hline 14 & Poems \\
\hline 15 & Practicing words with flashcards \\
\hline 16 & Practicing sounds in isolation and in context \\
\hline 17 & Presentation \\
\hline 18 & Reading aloud \\
\hline 19 & Recording voice in order to hear one's pronunciation \\
\hline 20 & Rehearsing sounds \\
\hline 21 & Silent and loud repetition \\
\hline 22 & Singing songs and creating rhymes \\
\hline 23 & Slowing down the pace of speaking for clear enunciation \\
\hline 24 & Speaking aloud \\
\hline 25 & Speaking silently to oneself \\
\hline 26 & Teaching pronunciation to other people \\
\hline 27 & Practicing tongue twisters \\
\hline 28 & Using a mirror \\
\hline 29 & Using a dictionary \\
\hline 30 & Using colors \\
\hline 31 & Using gestures and facial expressions to support the pronunciation of difficult words \\
\hline 32 & Using phonemic transcription \\
\hline & \\
\hline
\end{tabular}

Table 1 shows a number of strategies that language learners may use to learn pronunciation. LINCS as a strategy has not been mentioned in these strategies. Therefore, this study is an attempt to discuss the benefit of LINCS for learning FL pronunciation.

\subsection{LINCS strategy}

As mentioned above, the LINCS strategy consists of five steps these steps are as follows: 
First, list the target words to be learned and what information is important to remember.

Second, identify a reminding word in which mnemonic devices are created using the "keyword" strategy.

Third, note a LINCing story, which means that an association between the familiar word and the new word is generated by linking the meaning of the two words in some way with the help of a brief story or a sentence.

Fourth, create a LINCing picture, which refers to the information transformed into a visual image.

Fifth, self-test in which students test their memory of the new word. This can be done by either recalling the memory devices the words to be learned to try to state the definition, or by beginning with the definition of the words, recalling the memory devices, and trying to name the word. The LINCS strategy is based on the use of powerful memory-enhancement tactics. As Ellis (2000) points out, the steps of the LINCS strategy motivate students to focus on the critical elements of a vocabulary item, and then to use keyword mnemonic devices, mnemonic stories, visual imagery, associations with prior knowledge, and self-evaluation to enhance their memory of the meaning of the word and pronunciation.

The effect of the LINCS strategy on vocabulary learning has been examined in some studies. For example, Ellis' (2001) compared the effect of the Lincing Routine with sixth-grade students to students who had not used the Lincing Routine. The study found in the positive effect of gaining higher scores on social study vocabulary tests for the LINCS group rather than the control group, who did not use the strategy in learning social study vocabulary. In addition, Schumaker, Deshler, Woodruff, Hock, Bulgren, and Lenz, (2006) examined four strategies in reading instruction including the LINCS vocabulary strategy. The participants were divided into two groups: the experimental groups who received learning using the LINCS strategies, and the control group taught in traditional instruction. The results showed that the experimental groups produced a higher improvement in reading comprehension than the control groups. Similarly, Cantrell, et al (2010) examined the effect of multiple strategies, including the LINCS strategy for improving disabled students' reading comprehension. The results indicated that students in the LINCS group outscored other groups who did not use the LINCS strategy. Similar results were obtained from a study conducted by Albarakati (2016).

On the other hand, some studies found that LINCS as a strategy for learning vocabulary is not as useful as other strategies. For example, Harris, Schumaker, and Deshler, (2011) examined the effects of teaching high school students with learning disabilities (LD) and other students enrolled in general education classes a morphemic analysis strategy for analyzing and predicting the meaning of words. A comparisongroup design was used with random assignment of three intact classes to each of two conditions:

- The Word Mapping condition, where students learned the morphological analysis strategy

- The Vocabulary LINCing condition, where students learned a mnemonic strategy 
Word Mapping students earned higher scores on a test of morphological analysis than the students in the other group. Thus, students were able to learn generative and non-generative vocabulary strategies and could apply a generative strategy to analyze and create meaning for unknown words, an important skill while reading assignments and taking reading tests.

\subsection{Multimedia and language learning}

Vocabulary can be learned with the help of a computer. Computer-assisted pronunciation training (CAPT) recently is the field of study of many articles (see Mahdi \& Alkhatbbe, 2019). One of the technologies that can be enhanced by the use of computer-assisted pronunciation training is multimedia. The use of multimedia in vocabulary learning can provide language learners with opportunities to learn vocabulary in an effective and interesting way. Several studies were conducted to examine the effectiveness of multimedia on vocabulary learning (e.g., Aldera \& Mohsen, 2013; AlSeghayer, 2001; Chun \& Plass, 1996; Hulstijn, 2000; Jones, 2003, 2006; Jones \& Plass, 2003; Koren, 1999; Mahdi, 2017; Mohsen, 2016; Tsoua, Wang \& Li, 2002). These studies have revealed a number of encouraging results, which reveal that vocabulary learning with multimedia can be more effective than through the use of traditional learning methods.

The integration of multimedia for vocabulary learning helps learners create connections between the verbal and visual representational systems (Mayer \&Sims, 1994), resulting in an increase in vocabulary knowledge and create a positive effect on word recognition. Multimedia use for vocabulary learning takes different forms, depending on the teaching context and learners' needs. Chun and Plass (1997) pointed out that multimedia-assisted reading comprehension and vocabulary learning may meet with a lower amount of mental effort than the use of static pictures, and, as a result, students who used the text and picture annotations scored higher on the follow-up vocabulary test than students who used text and video annotations.

\subsection{Multimedia-assisted LINCS}

The combination of one strategy with other strategies proved as efficient in aiding the information retention and recall over a period of time (Takac, 2008). Therefore, using multimedia as an environment for the LINCS strategy can be useful and create opportunities for language learners to improve their achievement in language learning. The effect of the combination of LINCS strategy and multimedia in promoting EFL pronunciation has not yet thoroughly examined. The present study is an attempt to fill in this gap and explore the effect of using multimedia as an environment for LINCS to enhance EFL pronunciation. The study seeks to answer the following research question: What is the effect of multimedia-assisted LINCS on FL learners' pronunciation? 


\section{Methods}

To measure the effect of multimedia-assisted LINCS on pronunciation, three groups of Arab adult learners participated in this study. The control group received instruction in the form of traditional (i.e. teacher-led classes). The experimental groups worked with two ways of LINCS. The first one is multimedia-assisted LINCS and the second one is traditional LINCS.

\subsection{Research design}

This study follows the experimental design of the study in which three intact EFL university classes were randomly taught according to multimedia-assisted LINCS, traditional LINCS, and no LINCS. The experiment was conducted for a month, as shown in Figure 1.

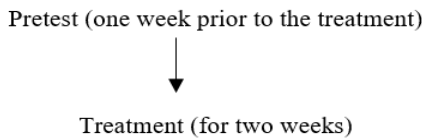

The participants were randomly divided into three groups: Multimedia-assisted LINCS, Traditional

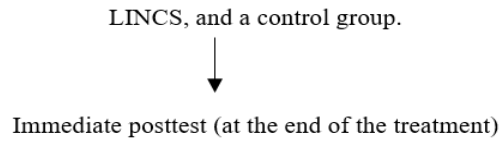

Fig. 1. Study design

\subsection{Participants}

The participants in the present study were 45 students from three intact EFL classes enrolled in the English Department at the University of Bisha, Saudi Arabia. The study was conducted in the first semester of the academic year 2018/2019. Their ages ranged from 19 to 24 years. Their average proficiency in English was categorized as intermediate based on the documents of the department. These students had been studying EFL for more than 7 years. The participants in all the groups were taught by the same instructor.

\subsection{Procedures}

One class was held with the EFL instructor prior to the beginning of the study. In the first session, the pretest was distributed to all participants in the three groups. The pre-test was administered in one regular session prior to the treatment. The participants were asked to read aloud 30 sentences and to record them (see Appendix A). Their recordings were saved on the desktop in the language lab to be used later in the 
analysis. In the second and third sessions, the target words were introduced (15 words in each session). The same content was taught to all the groups. However, the participants in each group were trained with a different strategy. Participants in the Multimedia-assisted LINCS group were taught using PowerPoint presentation which included the main parts of the LINCS strategy. Participants in the traditional LINCS were taught the same words using tradition LINCS as introduced in Ellis (2000). Participants in the control group were taught the same target words traditionally without any LINCS. The instructor pronounced the target words orally and the students repeated after him and then practiced these words individually. The words in the multimedia-assisted LINCS were presented in the following steps. First, the list of words that would be learned was presented. Second, the identifying step was performed by showing words from the native language (i.e. Arabic) that are similar in their pronunciation to the English words. Third, these words were used in context. The context was the website called YouGlish. The participants were asked to access this website and type each word and watched some videos in which this word occurred. Fourth, each word was shown with an image using a PowerPoint presentation. The aim of this step was to make a link that enabled the participants to recall the pronunciation of this word later on. Fifth, the participants were asked to evaluate themselves by pronouncing the target words. In the fourth session, the post-test was administered to all groups. The participants were asked to read aloud the same sentences as they appeared in the pre-test and to record them. Their recordings were saved on the desktop in the language lab to be used later for the data analysis.

\subsection{Testing procedure}

The test was developed by the researcher based on the words that are normally mispronounced as suggested by Marian, (2013). The pre-test consisted of 30 sentences based on these words. The examples were taken from the Longman Dictionary of Contemporary English. To evaluate the participants' improvement in pronunciation, the participants were asked to read and record a set of 30 isolated sentences. At the end of the treatment, a post-test for the three groups was administered to test participants' pronunciation of the target words. Again, their responses were recorded for further analysis.

\subsection{Recording and scoring}

In the pre- and post-tests, the participants were asked to read the sentences aloud and to record them. The recordings were made in the computer lab using headmounted microphones. Head-mounted microphones were used to maximize the robustness of the recordings. The recording steps were performed as follows: First, the participants were asked to check the equipment by recording two short sentences which were not included in the tests. Second, the participants were asked to read aloud the sentences of the test. If the learner felt that he had not pronounced the sentences correctly, he could repeat them and record them as many times as needed. Third, each participant should record all the 30 sentences and save them in one file. 
By the end of the study, each participant would have two files: the first file was for the pre-test and the second for the post-test. After the recording, these files were given to two raters. The recordings were scored independently by three non-native speakers of English. Each rater was asked to provide a score of pronunciation quality of each sentence on a 5-point scale based on Isaacs, Trofimovich, and Foote (2017).

Table 2. Isaacs et al. (2017) Comprehensibility global and analytical scale

\begin{tabular}{|c|l|}
\hline Comprehensibility level & \multicolumn{1}{c|}{ Overall description of comprehensibility } \\
\hline 5 & $\begin{array}{l}\text { Speech is effortless to understand. } \\
\text { Errors are rare and do not interfere with the message. }\end{array}$ \\
\hline 4 & $\begin{array}{l}\text { Speech requires little effort to understand. } \\
\text { Errors minimally interfere with the message. }\end{array}$ \\
\hline 3 & $\begin{array}{l}\text { Speech requires some effort to understand. } \\
\text { Errors somewhat interfere with the message. }\end{array}$ \\
\hline 2 & $\begin{array}{l}\text { Speech is effortful to understand. } \\
\text { Errors are detrimental to the message. }\end{array}$ \\
\hline 1 & $\begin{array}{l}\text { Speech is painstakingly effortful to understand. } \\
\text { Errors are detrimental to the message. }\end{array}$ \\
\hline UR & Unable to Rate the speech. \\
\hline
\end{tabular}

The raters' scores were first analysed to determine inter-rater reliability. A Cronbach's Alpha coefficient of . 88 was obtained, which can be considered good.

\subsection{Data analysis}

Descriptive statistical procedures were performed in this study to determine the effect of the LINCS strategy on EFL pronunciation. An ANOVA was conducted to determine the significance of the differences among the three groups. The level of significance was .05 for all statistical analyses. These results will be discussed in the next section.

\section{$4 \quad$ Results}

To answer the research question of whether the students' pronunciation achievement improved due to the use of multimedia-assisted LINCS, the mean and standard deviation across pre- and post-tests showed variation in the students' performance (Tables $3 \& 4$ ). The use of multimedia-assisted LINCS was assigned as the betweensubject variable, whereas the time of the tests was assigned as a within-subject independent variable. Results showed that a significant effect of LINCS existed from the pre- and post-test design. Results from ANOVA revealed that a significant effect existed among the three groups. The participants who used LINCS (either multimediaassisted LINCS or traditional LINCS) significantly outscored the control group in the post-test ( $M=13.6,12.46,7.26, S D=5.44,5.85,4.30$ respectively). However, the performance of the multimedia-assisted LINCS group over time was slightly higher than that of the traditional LINCS group but the difference was not significant $(M D$ $=1.33, p=.82$ ) as shown in Table 5 . 
Table 3. The effect of MLINCS, traditional LINCS, and traditional instruction

\begin{tabular}{|l|c|c|c|c|l|l|l|l|l|}
\hline & \multicolumn{2}{|l|}{ MLINC (N = 15) } & \multicolumn{2}{l|}{ TLINCS (N=15) } & \multicolumn{2}{l|}{ Control(N=15) } & \multicolumn{2}{l|}{ All Groups } & \multirow{2}{*}{ Sig. } \\
\cline { 2 - 9 } & M & SD & M & SD & M & SD & M & SD & \\
\hline Pre-test & 4.6 & 2.74 & 4.2 & 3.14 & 4.93 & 3.80 & 4.57 & 3.2 & .82 \\
\hline post test & 13.6 & 5.44 & 12.46 & 5.85 & 7.26 & 4.30 & 11.11 & 5.83 & .004 \\
\hline
\end{tabular}

Table 4. ANOVA results for $\mathrm{L} 2$ pronunciation tests

\begin{tabular}{|l|c|c|c|c|}
\hline & $\boldsymbol{D} \boldsymbol{f}$ & $\boldsymbol{M S}$ & $\boldsymbol{F}$ & $\boldsymbol{P}$ \\
\hline Between groups & 2 & 422.51 & 16.09 & $.000^{*}$ \\
\hline Within groups & 52 & 26.25 & & $.000^{*}$ \\
\hline
\end{tabular}

*The level of the sig. $=.05$

Post-hoc pairwise comparisons using Tukey HSD yielded significant differences among the three groups over time (Table 5).

Table 5. Tukey HSD post hoc test

\begin{tabular}{|l|l|l|c|c|}
\hline \multirow{5}{*}{ Dependent variables } & (I) Multimedia & (J) LINCS & Mean Differences (I-J) & Sig. \\
\cline { 2 - 5 } & MLINCS & TLINCS & 1.33 & .82 \\
\cline { 2 - 5 } & & Control group & 6.33 & .005 \\
\cline { 2 - 5 } & \multirow{3}{*}{ TLINCS } & MLINCS & -1.33 & .82 \\
\cline { 2 - 5 } & Control group & 5.20 & .025 \\
\cline { 2 - 5 } & \multirow{2}{*}{ Control group } & MLINC & -6.33 & .005 \\
\cline { 3 - 5 } & & TLINCS & -5.20 & .025 \\
\hline
\end{tabular}

The mean difference is significant at the .05 level

As shown in Table 5, the mean difference between multimedia-assisted LINCS and the control group was significant $(M D=6.33, \mathrm{Sig}=.005)$ which indicated that multimedia-assisted LINCS was more effective than learning FL pronunciation without LINCS. In addition, the mean difference between traditional LINCS and the control group was significant $(M D=5.20, S i g=.025)$ which indicated that traditional LINCS was effective in learning FL pronunciation. Moreover, the mean difference between multimedia-assisted LINCS and the traditional LINCS was not significant $(M D=1.33$, Sig=.82) which indicated that both multimedia-assisted LINCS and traditional LINCS are effective than learning FL pronunciation.

\section{Discussion}

This study sought to examine the effects of multimedia-assisted LINCS on learning English pronunciation. Three groups were engaged in this study to find out the potential effect of LINCS on learning pronunciation. The results revealed that there is a positive impact of using multimedia-assisted LINCS on learning pronunciation. The experimental group that used multimedia-assisted LINCS as a strategy to aid learning pronunciation outperformed the students in the control group where no LINCS was used. Moreover, the results indicated that LINCS as a strategy can be effective for 
learning English as a foreign language pronunciation. The use of LINCS either with multimedia assisted or traditionally is beneficial in learning English pronunciation.

The study results are in line with Clark and Paivio (1991) dual coding theory, which assumes that information is coded dually in the human mind either verbally (i.e., text and sounds) or non-verbally (i.e., picture and objects). These two systems are interconnected when words are represented by one system and can be activated by the other system or vice-versa (i.e. verbal activated by non-verbal). In this case, the spoken words were represented in different modalities. These modalities were in two different kinds: verbal (e.g. auditory) and non-verbal (e.g. imagery). According to Clark and Paivio (1991), learning foreign vocabulary involves successive verbal and non-verbal representations that are activated during initial study of the word pairs and during later efforts to retrieve translations. In this study, the auditory part of the representation was the Arabic words that pronounced similarly to the target English words. The participants made connections between the sound of the Arabic words and the sound of the English words. The imagery part of the representation was through presenting an image for each word. The images served as a reminder of the sound of each word. For example, the word cupboard was pronounced wrongly by most of the participants into /k^pəurd/. The word that is similar to the correct pronunciation is which is pronounced as $/ \mathrm{k} \wedge$ bək/. The focus here was on the vowel sound so this word served as a suitable connection. At the end of the experiment, the participants pronounced a number of words correctly and this was due to the simple connections of Arabic words. The use of context was necessary to enable the participants to be exposed to the authentic language in which these words were used.

\section{Conclusion}

This study explored the effectiveness of LINCS in learning FL pronunciation. In general, LINCS has been found as an effective tool to aid learning FL pronunciation. However, using multimedia-assisted LINCS for learning English pronunciation was found slightly superior to using LINCS when it is used traditionally. The participants learned the pronunciation of new English words better when they used LINCS than when they used the traditional way of learning. This study has generated several pedagogical implications for foreign language teachers. For example, second language instructors might benefit from the results of this study to present new FL words in a way that enhances learning the pronunciation of new words and increases the retention of new words.

There are several limitations to the current study. First, the small number of participants may threaten the validity of the study findings. Thus, a study with a large sample size would yield stronger evidence to generalize the findings. In addition, the participants in this study were adult university learners. So further studies could be conducted to explore the effect of LINCS on learning the pronunciation of FL among young learners, as age is a crucial factor for learning pronunciation. 


\section{$7 \quad$ References}

[1] Albarakati, M. (2016). The Effect of Vocabulary Lincing Routine for Learning Vocabulary to Students with Special Needs. Published MA Thesis, Southern Illinois University Edwardsville

[2] Aldera, A. \& Mohsen, M. (2013). Annotations in captioned animation: effects on vocabulary learning and listening skills. Computers and Education, 68, 60-75. https://doi.org/10.1016/j.compedu.2013.04.018

[3] Al-Seghayer, K. (2001). The effect of multimedia annotation modes on L2 vocabulary acquisition: A comparative study. Language Learning \& Technology, 5(1), 202-232.

[4] Cantrell, S. C., Almasi, J. F., Carter, J. C., Rintamaa, M., \& Madden, A. (2010). The impact of a strategy-based intervention on the comprehension and strategy use of struggling adolescent readers. Journal of Educational Psychology, 102(2), 257-280. http://dx.doi.org/ $\underline{10.1037 / \mathrm{a} 0018212}$

[5] Chun, D. M., \& Plass, J. L. (1996). Effects of multimedia annotations on vocabulary acquisition. The modern language journal, 80(2), 183-198. https://doi.org/10.1111/j.15404781.1996.tb01159.x

[6] Chun, D. M., \& Plass, J. L. (1997). Research on text comprehension in multimedia environments. Language Learning \& Technology, 1(1), 60-81.

[7] Clark, J. M., \& Paivio, A. (1991). Dual coding theory and education. Educational psychology review, 3(3), 149-210. https://doi.org/10.1007/bf01320076

[8] Ellis, E. S. (2000). The LINCS Vocabulary Strategy, Edge Enterprises, Inc., Lawrence, Kansas

[9] Ellis, E. S. (2001). The Vocabulary LINCing Routine (3rd ed). Lawrence: Edge

[10] Gilakjani, A. P., \& Ahmadi, M. R. (2011). Why is pronunciation so difficult to learn? English Language Teaching, 4(3), 74-83. https://doi.org/10.5539/elt.v4n3p74

[11] Harris, M. L., Schumaker, J. B., \& Deshler, D. D. (2011). The effects of strategic morphological analysis instruction on the vocabulary performance of secondary students with and without disabilities. Learning Disability Quarterly, 34(1), 17-33. https://doi.org/10.11 $\underline{77 \% 2 \mathrm{~F} 073194871103400102}$

[12] Hulstijn, J. H. (1992). Retention of inferred and given word meanings: Experiments in incidental vocabulary learning. In P. J. L. Arnaud \& H. Béjoint (Eds.) Vocabulary and applied linguistics (pp. 113-125). London: Macmillan. https://doi.org/10.1007/978-1-349$12396-4 \quad 11$

[13] Hulstijn, J. H. (2000). The Use of Computer Technology in Experimental Studies of Second Language Acquisition: A Survey of Some Techniques and Some Ongoing Studies. Language Learning \& Technology, 3(2), 32-43. http://llt.msu.edu/vol3 num2/hulstijn/index.html

[14] Isaacs, T., Trofimovich, P., \& Foote, J. A. (2017). Developing a user-oriented second language comprehensibility scale for English-medium universities. Language Testing, DOI: https://doi.org/10.1177/0265532217703433

[15] Iwashita, N., Brown, A., McNamara, T., \& O’Hagan, S. (2008). Assessed levels of second language speaking nproficiency: How distinct? Applied Linguistics, 29(1), 24-49. https://doi.org/10.1093/applin/amm017

[16] Jenkins, J. (2000). The phonology of English as an International Language. Oxford, England: Oxford University Press.

[17] Jones, L. (2003). Supporting listening comprehension and vocabulary acquisition with multimedia annotations: The students' voice. CALICO Journal, 21(1), 41-65. https://doi.org/10.1558/cj.v21i1.41-65 
[18] Jones, L. C. (2006). Effects of collaboration and multimedia annotations on vocabulary learning and listening comprehension. CALICO Journal, 24 (1) 33-58. https://doi.org/10.1 558/cj.v24i1.33-58

[19] Jones, L. C., \& Plass, J. L. (2003). Supporting listening comprehension and vocabulary acquisition in French with multimedia annotations. The Modern Language Journal, 86(4), 546-561. https://doi.org/10.1111/1540-4781.00160

[20] Kang, O. (2010). ESL learners' attitudes toward pronunciation instruction and varieties of English. In J. Levis \& K. LeVelle (Eds.), Proceedings of the 1st Pronunciation in Second Language Learning and Teaching Conference, Iowa State University, Sept. 2009. (pp. 105118), Ames, IA: Iowa State University. https://doi.org/10.31274/ans air-180814-164

[21] Mahdi, H. S. (2017). The effect of key-words video captions on vocabulary learning through mobile-assisted language learning, International Journal of English Linguistics, 7(4), 1-7 https://doi.org/10.5539/ijel.v7n4p1

[22] Mahdi, H. S. \& Alkhateeb, A. A. (2019). The effectiveness of computer-assisted pronunciation training: A meta-analysis, Review of Education, DOI: 10.1002/rev3.3165

[23] Marian, J. (2013). Improve your English Pronunciation and Learn over 500 Commonly Mispronounced Words, Sewanstraße 217, 10319, Berlin, Germany

[24] Mayer, R. E., \& Sims, V. K. (1994). For whom is a picture worth a thousand words? Extensions of a dual-coding theory of multimedia learning. Journal of educational psychology, 86(3), 389-401. https://doi.org/10.1037//0022-0663.86.3.389

[25] Mohsen, M. A. (2016). Effects of help options in a multimedia listening environment on L2 vocabulary acquisition. Computer Assisted Language Learning, 29 (7), 1220-1237 http://doi.org/10.1080/09588221.2016.1210645

[26] Morley, J. (1991). The pronunciation component in teaching English to speakers of other languages. TESOL Quarterly, 25(3), 481-520. https://doi.org/10.2307/3586981

[27] Nation, I. S. P. (2001). Learning Vocabulary in Another Language. Cambridge: Cambridge University Press.

[28] Oxford, R. L. \& Scarcella, R.C. (1994). Second language vocabulary learning among adults: State of the art in vocabulary instruction. System, 22, 231-243 https://doi.org/10.10 16/0346-251X(94)90059-0

[29] Paivio, A. (1971). Imagery and verbal processes. New York: Holt, Rinehart, \& Winston. Reprinted 1979, Hillsdale, NJ: Lawrence Erlbaum Associate.

[30] Paivio, A. (1986). Mental representations: A dual coding approach. Oxford, UK: Oxford University Press

[31] Pawlak, M. (2010). Designing and piloting a tool for the measurement of the use of pronunciation learning strategies. Research in Language, 8, 1-14. DOI 10.2478/v10015-0100005-6

[32] Pennington, M. C. \& Richards, J. C. (1986). Pronunciation revisited. TESOL Quarterly, 20(2), 207-225. https://doi.org/10.2307/3586541

[33] Peterson, S. S. (2000). Pronunciation Learning Strategies: A First Look.

[34] Schumaker, J. B., Deshler, D. D., Woodruff, S. K., Hock, M., Bulgren, J. A., \& Lenz, B. K. (2006). Reading strategy interventions: Can literacy outcomes be enhanced for at-risk adolescents? Teaching Exceptional Children,38(3),64,68 https://doi.org/10.11 $77 / 004005990603800310$

[35] Szyszka, M. (2017). Pronunciation learning strategies and language anxiety: In search of an interplay, Springer International Publishing

[36] Takac, V. P. (2008). Vocabulary learning strategies and foreign language acquisition, Multilingual Matters Ltd 
[37] Tsoua, W., Wang, W., \& Li, H. (2002). How computers facilitate English foreign language learners acquire English abstract words. Computers \& Education, 39 (4), 415-428. https://doi.org/10.1016/S0360-1315(02)00078-7

[38] Wesche, M. B., \& Paribakht, T. S. (2000). Reading-based exercises in second language vocabulary learning: An introspective study. The Modern Language Journal, 84(2), 196213. https://doi.org/10.1111/0026-7902.00062

[39] Wong, B. (2004). Learning about learning disabilities (3rd ed). Oxford: Elsevier Academic Press.

\section{Author}

Hassan Saleh Mahdi is an assistant professor of applied linguistics in the department of English, University of Bisha, Saudi Arabia. His research interests are computer-assisted language learning (CALL), Mobile-assisted language learning (MALL), second language vocabulary acquisition. He has published a number of articles related to these topics. ORCID: 0000-0003-4023-8219

Article submitted 2019-02-21. Resubmitted 2019-04-04. Final acceptance 2019-04-10. Final version published as submitted by the authors. 


\section{Appendix A The sentences used in the study}

\begin{tabular}{|l|l|}
\hline word & Sentence \\
\hline almond & I put an almond in a low oven for him \\
\hline archive & The archive still left a good deal to be desired. \\
\hline asthma & You have an asthma attack if you do this. \\
\hline banquet & A huge banquet was planned to celebrate the city's party. \\
\hline boutique & He stood outside the boutique and met his friend. \\
\hline cache & High-speed cache memory is expensive. \\
\hline chaos & There was total chaos on the road. \\
\hline chassis & It will be suitable and can sit low in a chassis. \\
\hline chateau & $\begin{array}{c}\text { Elizabeth was still residing at her chateau near London with her } \\
\text { children. }\end{array}$ \\
\hline choir & I have always sung in choirs. \\
\hline cliché & He seemed to believe that old cliché about women. \\
\hline coup & Haiti's president was deposed in a military coup. \\
\hline cupboard & The cupboard doors were open. \\
\hline debris & She was hit by flying debris from the blast. \\
\hline draught & Can you close the window? I am in a draught. \\
\hline elite & For them an elite must prove itself. \\
\hline façade & It is an impressive building with a red brick façade. \\
\hline gauge & The petrol gauge is still on full. \\
\hline gigantic & These gigantic creatures became extinct in this period. \\
\hline Heir & John was the sole heir to his father. \\
\hline infamous & This area is infamous for drugs and crimes. \\
\hline lenient & His parents are too lenient with him. \\
\hline niche & Sara found her niche at the bank. \\
\hline plumber & The plumber found plastic bags in the toilet. \\
\hline queue & We stood in a queue for half an hour. \\
\hline receipt & Keep your receipt in case you want to bring it back. \\
\hline recipe & I have found a great recipe for this meal. \\
\hline sour & Ali tested the drink. It was sour. \\
\hline subtle & There are subtle differences between the pictures. \\
\hline suite & Ahmed was staying in a suite on the fifth floor. \\
\hline
\end{tabular}

